\title{
INTEGRATION INTO CANADIAN SOCIETY: HOW ARMENIAN SYRIAN MILLENNIAL REFUGEES USE SOCIAL MEDIA
}

\author{
Alyssa Racco \\ Faculty of Education, York University, Toronto, Canada
}

\begin{abstract}
Using a conceptual framework that builds on the constructs of community of practice (Homles \& Meyerhoff, 1990; Lave \& Wenger 1998; Wenger 1998) and superdiversity (Blommaert, 2013; Blommaert \& Rampton, 2012; J $\phi r g e n s e n$, Karrebaek, Madsen, \& Møller, 2011; Vertovec, 2007), this study reports on the ways Armenian Syrian millennial refugees access information via social media. Findings are based on data collected through participant observations, interviews and survey protocols. The study showed the use of semiotic resources as social media allowed respondents to extend the social implicatures of language beyond their verbal proficiency levels.
\end{abstract}

\section{KEYWORDS}

Armenian Syrian Millennial Refugee, Snapchat, Communication, Social Inclusion

\section{INTRODUCTION}

This paper explores how Armenian Syrian millennial refugees utilize text and image as a form of communication on Snapchat. According to Caidi and Allard (2005), cited by Lloyd, Kennan, Thompson, and Qayyu (2013), very little is currently known about "the ways newcomers and longer established immigrants communicate, locate, and access content in forms that are understandable and useable to them" (Lloyd, Kennan, Thompson, \& Qayyum, 2013, p.5). The literature indicates that social inclusion is difficult for refugees because they lack English proficiency (Lloyd, Kennan, Thompson, \& Qayyum, 2013, p. 17). As a result, they are unable to be part of the creation or sharing of information. This, then, perpetuates their social exclusion: Caidi and Allard (2005), cited by Lloyd, Lipu, and Kennan (2010), who have studied this issue [social exclusion as an information problem] in Canada, suggest that a lack of access to information creates barriers that prohibit full participation in education, work, and everyday life" (Lloyd, Lipu, \& Kennan, 2010, pp. 45-46).

In this paper, I examine how millennials' use of visuals and social media platforms helps to mitigate their social exclusion. Specifically, I explore if and how Armenian Syrian millennial refugees who frequent the Armenian Community Centre in Toronto access and communicate content through emojis and Snapchat.

\section{LITERATURE REVIEW}

\subsection{Definitions and Data}

According to the United Nations Convention and Protocol Relating to the Status of Refugees (1989), a refugee is: "... owing to a well-founded fear of being persecuted for reasons of race, 
religion, nationality, memberships of a particular social group, or political opinion, is outside the country of his nationality and is unable or, owing to such fear, is unwilling to avail himself of the protection of that country" (p. 14). Because of the war in Syria, "More than half of the citizens of Syria have been forcibly displaced" (Pottie, Greenaway, Hassan, Hui, \& Kirmayer, 2016, p. 208). As a result: "Repeated displacements have been a striking feature of the Syrian conflict, as frontlines keep shifting and formerly safe areas become embroiled in conflict. Experiences of violence are compounded by stressors, such as precarious living conditions, loss of family and supports, social isolation, discrimination and exploitation, and uncertainty about the future" (p. 208). Many Syrians have fled their country for refuge.

According to Statistics Canada (2018), during 2016, a total of 319285 refugees were living in Toronto and a total of 482665 refugees were living in Ontario (Census Profile, 2016 Census). According to Barber and Ramsay (2017), citing Zilio (2016): "From November 2015 to January 2017, Canada accepted 40,081 refugees from Syria alone (p. 348). Among those, 15 percent were between the ages of 15 and 24 and 48 percent were between the ages of 25 and 64 (Population Profile: Syrian Refugees). For the purposes of $\mathrm{m}$ study, "millennial" is defined as a person born between the years 1982 and 2005 (Howe \& Strauss, 2007, p .3).

\subsection{Barriers to Language Learning}

Refugees do not have the same academic competencies as native English speakers; nor do they hold the oral or linguistic proficiency: "the level of English proficiency, and in particular, reading and writing proficiency, prevents this group from engaging effectively with text based digital and print information commonly used to deliver and disseminate information" (Lloyd, Kennan, Thompson, \& Qayyum, 2013, p. 17). This barrier to access information is a major alienation factor for refugees.

Lloyd, Kennan, Thompson, and Qayyum (2013) assert: "information - and the information literacy practices and related skills which enable people to access information and to critically evaluate and use information are... [a] prerequisite for social inclusion...This knowledge is derived through information and appropriate information literacy practice" (Lloyd, Kennan, Thompson, \& Qayyum, 2013, p. 2). According to Lloyd (2006; 2010), as cited by Lloyd, Annemree et al. (2013), information literacy is, "understood as a socially situated practice and is defined as a way of knowing an information landscape by developing practices and skills that will enable an individual to critically analyse...." (p. 5). Moreover, according to Lloyd (2010): "As a social practice, information literacy is understood not only to be in the possession of an individual, but also the possession of the community. It is there constructed as a co-construction brought about by those who are co-located and participating in the everyday life of a community" (p. 6). We see here how lack of literacy is understood as the "underlying cause of social exclusion" (p. 4). Moreover, information literacy and knowledge of a particular society is rooted in the "language of 'sayings' and manifested in 'doings"' (p. 7), which is difficult for refugees to decipher because of their limited English language proficiency. Without access to this "nuanced and taken-for-granted information" (p. 16), refugees are unable to obtain the knowledge needed to take part in the information literacy practices of a society because they do not possess information literacy.

Their social exclusion is the direct result of refugees' inability to access information literacy. The risks of socially excluded individuals, according to Vinson (2009) as cited by Lloyd, Annemare, et al. 2013 include: " 'limited support network, inability to access the labour market, alienation from society and poorer education outcomes' which can lead to further risk of disenfranchisement" (p. 3). Refugees who are socially excluded from information because of their lack of literacy may never "fully settle, [fail] to recognize and take up opportunities, and 
[fail] to participate in society as full citizens" (p. 4). In order to participate in society, refugees must have social information defined here as "information embodied within social networks which is difficult to articulate or express in written form, as it is drawn from real life experiences ... These types of information are inherently tied to information sharing, and often shared via storytelling..." (p. 15). However, because refugees have difficulty accessing textbased information, and are unable to decipher nuanced information, they are unable to engage fully in real life experiences related to the character of the landscape. Thus, refugees risk being perpetually socially excluded.

This said, the risks of social exclusion are less pronounced for millennials, who have access to the Internet. Hershatter, Andrea and Epstein (2010) refer to millennials as 'digital natives' (p. 212) because "technologies are indigenous to [them]...technology for them is a sixth sense, as a way of knowing and interacting with the world" (pp. 212-213). Hershatter, Andrea and Epstein (2010), citing Tapscott (2009), explain that: "Millennials have developed unique abilities as fluent visual think[ers]" (p. 213). This assertion supports Lu et al. (2016)'s findings on emoji usage of smartphone users: "Emojis...have been widely used as complements or surrogates of plain text" (p. 770). It appears that the visuals replace the written word. Ivkovic and Lotherington (2010) explain: "The choice, prominence and juxtaposition of languages in cyberspace create an important dimension of global linguistic ecology, and the channels, choices and limits in languages in cyberspace affect fragile balances in individual and social linguistic repertoires" (p. 32). However, emojis, as a linguistic repertoire of their own, introduce a new language into cyberspace. Arguably, emojis are able to enhance or completely replace the need for written text.

In arguing for emojis ability to replace the written word because of the rich and nuanced meaning associated with them. Lu, et al. (2016) assert: "The compactness of emojis reduces the effort of input; the rich semantics they convey expresses ideas and emotions more vividly; emojis do not have language barriers, making it possible to communicate among users from different countries...making them into a "ubiquitous language" that bridges everyone" (p. 770). Similarly, Evans (2017) asserts: "emojis facilitate a better calibration and expression of our emotions in digital communication" (p. 34), when compared to text-based communication. Hence, emojis replace the need for the written English word because they are their own language. These nuanced symbols have specific meanings but do not require fluency in any particular language.

Through Snapchat, with emojis, refugee millennielas can mitigate their experience of social exclusion. Kennan, Mary Anne, et al. (2011) assert: "Social inclusion requires an ability to develop effective information practices that enable connection to compliance, making available everyday and nuanced information that constitute elements of the information landscape which need to be accessed and understood in order to participate in their adopted community" (p. 191). The complex and nuanced meanings associated with each emoji would allow millennial refugees to access and understand everyday items in the information landscape, enabling participation in their adopted Snapchat community.

\section{CONCEPTUAL FrameWORKS}

This study was embedded in a meshing of two conceptual frameworks: community of practice (CofP) and superdiversity theory. In this study, respondents' registers on social media, including the use of Snapchat and emojis, create a community of practice that allows them to access information and mitigates their social exclusion. 


\subsection{Community of Practice}

Community of Practice (CofP) theory focuses on "what members do: the practice of activities that indicate that they belong to the group, and the extent to which they belong" (Holmes \& Meyerhoff, 1990, p. 175). The practice of meaning being negotiated within forming communities is the foundation of this theory (Wenger, 1999, p. 72). Wenger (1998) stipulates the three defining components of a CofP: "mutual engagement, a joint enterprise, [and] a shared repertoire" (p. 73). Wenger (1998) describes mutual engagement as: "people are engaged in actions whose meaning they negotiate with one another" (p. 73). Next, members of CofP share a joint enterprise: participants negotiate and collectively pursue an enterprise which thereby belongs to them, i.e., the group as a whole and each individual (Wenger, 1998, p. 77). Finally, a shared repertoire, according to Wenger (1998), is the practice which includes "routines, words, tools, ways of doing things, stories, gestures, symbols, genres, actions, or concepts that the community has produced or adopted in the course of its existence, and which have become part of its practice" (p. 83). Armenian Syrian millennial refugees are part of a community that includes a shared repertoire that allows them to bypass text script literacy. According to Lave and Wenger (1998), this common repertoire results from practice: ways of doing and approaching things that are shared to some significant extent among members (p. 2). On social media, the shared knowledge of the nuanced meaning of emojis is enhanced through communication. Because CoPs do not require homogeneity - rather negotiation of difference they are able to thrive within superdiverse social contexts, a theme to which I now turn.

\subsection{Superdiversity}

Superdiversity is a notion "intended to underline a level and kind of complexity...distinguished by a dynamic interplay of variables among...multiple-origin, transnationally connected, socioeconomically differentiated and legally stratified" (Vertovec, 2007, p. 1024) individuals. Vertovec (2007) highlights the differences between diversity and superdiversity. He explains diversity as one-dimensional, concerned with "ethnicity or country of origin" (Vertovec, 2007, p. 1025), and superdiversity as complex and multifaceted. Vertovec (2007) lists the variety of variables that determine superdiversity: "differential immigration statuses and their concomitant entitlements and restrictions of rights, divergent labour market experiences, discrete gender and age profiles, patterns of spatial distributions, and mixed local area responses by service providers and residents" (p. 1025). Similarly, Blommaert and Rampton (2012) differentiate superdiversity from diversity by the amount of variables entailed: "a tremendous increase in the categories of immigrants, not only in terms of nationality, ethnicity, language and religion, but also in terms of motives, patterns, and itineraries of migration, process of insertion into the labour and housing markets of host societies, and so on" (p. 7) characterizes superdiversity. However, Vertovec (2007) explicitly qualifies that it is "the interplay of these factors" (p. 1025) that constitutes what is meant by 'super-diversity'.

\subsubsection{Superdiversity in Relation to Language}

Jørgensen, Karrebæk, Madsen and Møller (2011) explain that the current sociocultural construction of a language "rarely represent[s] real-life language use" (p. 27): "The idea of separate languages as bounded systems of specific linguistic features belonging together ... is found to be insufficient to capture the reality of language use, at least in late modern superdiverse societies, and perhaps altogether" (p. 27). Language instead is understood as the "use [of] linguistic features as semiotic resources" (p. 29). Language is considered individual because "no two people share precisely the same features...the same pronunciations" (p. 35) 
and social because "every feature we do 'know' or 'possess', we share with somebody else" (p. $35)$.

The Internet and ICTs, "synchronous with the new forms of migration - have created a "network society" (Blommaert, 2013, citing Castella, 1996, p. 1) necessitating the development of "new forms of human communication" (Blommaert, 2013, p. 1). These new forms of communication, "shape new norms, and so acquire a potential to perpetually reshuffle the linguistic-symbolic hierarchies" (p. 1). As a result, social lives are organized "in relation to many competing norms and complementary ones - a feature of sociolinguistic superdiversity...call[ed] polycentricity" (p. 1). An individual's identity therefore, may have many 'centres' all with their own sets of norms, reflected in their "communicative competence" (p. 1). These many centres are also referred to as "registers" (Blommaert, 2013, citing Agha, 2007, p. 2) and are what enables us to "shift from one set of norms (those in the classroom, for instance) into another (say, those on Facebook)" (p. 2). Registers of communicative competencies are chosen based on functionality "within the specific niches in which we intend to deploy them" (p. 2). These different registers additionally contribute to a superdiverse society.

An important factor that determines an individual's social integration is determined by their success in acquiring the necessary registers to function in different aspects of the society in which they live. Blommaert (2013) asserts: "Superdiverse social environments are intensely polycentric and, thus, put high demands on register development for those who live and act in them" (p. 3). These pressures are excessive for on immigrants who have to acquire the resources to navigate different sub-cultures of society. (p. 2). The linguistic-symbolic hierarchy, derived from a monofocal bias (p. 2) within a society, impedes immigrants' integration (p. 2): "Immigrants are increasingly subjected to pressures to acquire the standard varieties of the national languages of their host societies, and this pressure is driven by a monofocal and generative view of 'standard' as the unique instrument for integration" (p. 3). This expectation is somewhat unrealistic when considering that immigrants, as citizens of a particular society, are expected to integrate into "the many niches that compose their actual social environment" (p. 2).

The notion of integration is directly related to that of citizenship. In order to appear to be a citizen, an individual must be able to seamlessly integrate into a given society. However, without access to semiotic resources associated with that culture, individual may find themselves perpetually excluded. Blommaert (2013) states:

We expect [immigrants] not just to pass the mandatory language test administered by the administration in charge of immigration; we also expect them to be fluent in the register of education, of labor, of gender, age and so forth - we expect them to be 'fully' integrated in every niche we detect in society. Failing that, immigrants will perpetually be regarded as 'dis-citizens'. (3)

'We' refers to those who create and refuse to modify the 'standard'. As a result, "the current institutionalized sociolinguistic face of citizenship in a growing number of countries...is sociolinguistically ludicrous" (ibid, p. 3).

Notwithstanding, in this study I show how Armenian Syrian millennial refugees are able to mitigate their social exclusion through participation in an online community of practice created on social media that involve use of a semiotic system comprised of emojis and their nuanced meanings. I view my investigation as a contribution to the growing body of work that grapples with the ways refugees mitigate social exclusion and, through their participation, negotiate membership in new communities to which they previously did not have access (Schecter, 2015). 


\section{RESEARCH METHODOLOGY}

In this study, I employ a qualitative case study approach in order to explore my research interests in Armenian Syrian refugee millenneials' uses of social media to communicate. I have tried to elicit what Geertz (1973) described as "thick descriptions" of respondents' stories and views to captive and subsequently render an emic position. I then use this information to understand and interpret the complexity of the respondents' behaviours and tendencies while using social media.

Data for this study was collected through participant observations, interviews and surveys in March of 2018. The respondents were observed virtually, and interviewed and surveyed individually, in person.

\subsection{Research Questions}

I have used the following research questions as a heuristic for my inquiry:

1. What issues related to the use of social media arise for respondents as they make efforts to adapt to their New World habitat and to continue to maintain connections with issues individuals and cultural phenomena related to their linguistic and cultural heritage?

2. What themes emerged related to the lived experiences of millennial refugees through their Snapchat communications?

3. In what ways do the devices offered by Snapchat complement and support development of language and literacy on the part of this demographic cohort?

\subsection{Site and Respondents}

The site of my research project was the Armenian Community Centre in North York; the virtual site, Snapchat. All of the candidates are of Armenian descent. All speak Armenian. Pseudonyms have been given to all of the respondents to protect their identity and safeguard any confidential information that may have been divulged during the research study.

There are four respondents: Ari, Sarine, Atom and Tamar. Ari is a twenty-year-old male who arrived to Canada, from Syria, one year and five months ago, in 2017. He credits the Armenian Community Centre for his status as a salaried employee. Sarine is a twenty-four-year-old female who came to Canada, from Syria, one year and seven months prior to being interviewed, in 2016. Atom is an eighteen-year-old male who came to Canada, from Syria, three weeks prior to being interviewed, in 2018. Tamar is an eighteen-year-old female who came to Canada, from Syria, 9 months prior to being interviewed, in 2017.

\section{FINDINGS}

\subsection{Current English Education}

Only one respondent is currently enrolled in an English learning program; however, the remaining three respondents indicated they learned English in school in Syria. The participant enrolled in an English language program takes her classes at a secondary school. During the day Tamar is enrolled in English as a Second Language (ESL) classes. However, she also indicated that English was taught in Syria: "I take classes because I want to know English more. I did not learn enough to speak fluently, when I was in Syria" (Tamar). 
Ari, Sarine and Atom all indicated that they watch television and movies and listen to music in English. Ari answered: "I watch and listen to things to learn new words and sayings like the ones the translation apps do not get right." Sarine revealed: "Almost everything I watch and listen to is in English but sometimes also Armenian and Arabic." Tamar stated: "Yes all the time. I learn new words. Now I only watch and listen in English because I got better." Atom explained that because both parents were fluent in English, it was frequently spoken in the home and therefore had the opportunity to improve his English proficiency. None of the participants identified themselves as fluent English speakers.

\subsection{Communicating with Syria}

The respondents used different languages and communication platforms to speak to different groups of people. Ari stated: "I only speak to them in Armenian and Arabic. My family Armenian and my friends Arabic. My family we speak on the phone but my friends on social media like Snapchat, Facebook and FaceTime. My friends from here we speak English." Sarine revealed: "When we talk it is in Armenian or Arabic. Friends on Facebook and Snapchat and family on the phone. I send pictures to my friends on Snapchat and videos sometimes to show them life here. But everyone from here that I met I speak in English." Atom clarified: "I speak Armenian to my family only on the phone. My friends in English but usually on Facebook or Instagram or Snapchat." Tamar disclosed: "Armenian to my family because we speak Armenian. All my friends we speak Arabic so I talk to them in Arabic. I use some apps on my phone to message friends like Kik, Facebook and Snapchat. All my friends from Canada I talk to them in English." The respondents indicated a tendency to communicate via social media platforms when communicating with friends. However, all of the respondents indicated they called their families and spoke to them on the phone rather than sending them a message or picture. Also, all English speaking friends were spoken to in English. When probed, all respondents said they did not feel as though they had any difficulty communicating with friends in English.

\subsection{Social Media Use}

When surveyed, all four respondents indicated they had been using social media for over one year. Ari indicated he began using social media at the age of 14; Sarine, at the age of 13; Atom, at the age of 12; and Tamar, at the age of 13 . When surveyed, all four respondents revealed that they used Facebook, Instagram and Snapchat. Two of the four participants indicated they also used LinkedIn. Survey results also indicated that all of the respondents accessed social media apps via smartphones, two out of four, via laptop, and one of the four, via tablets. Additionally, the survey indicated that all four respondents' phones and keyboards were set-up in English. This said, half of respondents often switch their keyboard language between English, Armenian and Arabic. Sarine clarified: "I switch my keyboard language when I talk to my family. That way I can talk to them in Armenian - it's a different language you know." Tamar revealed: "When I do not know a word in English I search it up in Armenian. When I talk to my friends and we don't speak English, I switch the keyboard. Most of them do not know English very well."

\subsubsection{Time Spent on Social Media Platforms}

All respondents indicated that they used social media 'a lot' (Table 1). There were significant differences between how often the social media apps were opened each day with a range of 50 to 300 plus. Additionally, respondents indicated that they spent between an hour to three hours plus a day on social media. All respondents indicated a tendency to use social media in the evening, especially before they went to sleep. 
Table 1. Time of Social Media Usage

\begin{tabular}{|c|c|c|}
\hline Time & \multicolumn{2}{|c|}{ Responses } \\
\hline How often is social media used? & $\begin{array}{l}\text { Ari: } \\
\text { Sarine: } \\
\text { Atom: } \\
\text { Tamar: }\end{array}$ & $\begin{array}{l}\text { "A lot!" [laughs to himself] } \\
\text { "Everyday. [laughs] All the time." } \\
\text { "A lot but I think my friends use it } \\
\text { more." } \\
\text { "All the time." }\end{array}$ \\
\hline Amount of times social media apps are opened & $\begin{array}{l}\text { Ari: } \\
\text { Sarine: } \\
\text { Atom: } \\
\text { Tamar: }\end{array}$ & $\begin{array}{l}\text { [Scratches head with right hand. } \\
\text { Right hand resting on forehead] "I } \\
\text { don't know like } 200 . " \\
\text { "More than } 200 \text { times a day for } \\
\text { sure." } \\
\text { "50 times per day, on average." } \\
\text { "I don't know. [laughs] If I had to } \\
\text { guess more than } 300 . "\end{array}$ \\
\hline Time Spent & $\begin{array}{l}\text { Ari: } \\
\text { Sarine: } \\
\text { Atom: } \\
\text { Tamar: }\end{array}$ & $\begin{array}{l}\text { "It depends. Like } 2 \text { hours total." } \\
\text { "2 hours plus. Some days a lot more, } \\
\text { like if I am bored." } \\
\text { "About an hour." } \\
\text { "Maybe } 3 \text { hours average." }\end{array}$ \\
\hline Part of day social media is used most & $\begin{array}{l}\text { Ari: } \\
\text { Sarine: } \\
\text { Atom: } \\
\text { Tamar: }\end{array}$ & $\begin{array}{l}\text { "The morning like when I wake up } \\
\text { and before I go to sleep. I guess in } \\
\text { bed the most." } \\
\text { "When I get up in the morning and } \\
\text { before I go to bed at night." } \\
\text { "During the evening." } \\
\text { "Most in the morning and evening } \\
\text { but before bed is when I am on } \\
\text { longest. I don't sleep sometimes } \\
\text { because I am on my phone talking } \\
\text { to my friends." }\end{array}$ \\
\hline
\end{tabular}

\subsubsection{Most Frequently Accessed Parts of Social Media}

Each respondent identified a different part of social media platforms as most frequented. Ari answered: "On Facebook I like to look at my newsfeed for articles to read and videos to watch. On Snapchat the news stories - I follow DailyMail, and CNN ." Sarine narrated: "On Instagram the Newsfeed and Explore pages to look at pictures. I follow photographers and architects mostly so I like looking at their pictures. On Snapchat I like reading articles or watching videos about the news. I follow some news channels like Stay Tuned, and some pop culture ones like Cosmo and People." Atom stated: "On Facebook I like groups to discuss particular topics and get info. On Snapchat: taking pictures. I am subscribed to the CNN channel on Snapchat." Tamar explained: "I think I use it for the pictures most so the part for pictures. On Snapchat I follow MTV and Cosmo and DailyMail for celebrity stuff." All four respondents indicated they were subscribed to pop culture or news accounts, or both, on Snapchat, that they watched daily. A subscription is a free feature on Snapchat that activated by a user through swiping upwards on an account. Even though unsubscribed users are able to see news and popular culture channels, scribed users are notified when the channel is updated with new content. 


\subsection{Communication}

All four respondents stated that emojis or pictures were the easiest to use. Ari responded: "Emojis because they are easy and quick." Sarine explained: "A picture just says what your message is or the emojis can mean things all by themselves. They're like a message." Atom answered: "I think pictures and emojis but more emojis. They are easier." Tamar replied: "Emojis with a picture because it makes it easy to communicate." All four respondents opined pictures and emojis and the most and easiest to use form of communication.

\subsubsection{Use of Different Communication Methods}

Words were used by three of the four respondents to leave a response or remark on a social media post (Table 2). Atom explained that words were best suited to explain a scientific concept. Pictures were used "all the time" by two of the four respondents because they allowed their friends and family to know exactly what they are doing and where they are. Sarine stated that pictures were her main source of communication on social media platforms and Atom used pictures to analyze scientific diagrams in a group chat. All four respondents asserted the ease, clarity, and efficiency of communicating through visual images.

Table 2. Communication Methods

\begin{tabular}{|c|c|}
\hline Communication Method & Responses \\
\hline Words & $\begin{array}{ll}\text { Ari: } & \text { "To type a quick message I guess or } \\
\text { leave on comment." } & \\
\text { Sarine: "To answer a question or leave a } \\
\text { comment." } \\
\text { Atom: "To write on my Snapchat stories } \\
\text { and write on people's walls on } \\
\text { Tacebook" } \\
\text { Tamar: "When messaging in a group or } \\
\text { explaining a concept." }\end{array}$ \\
\hline Pictures & $\begin{array}{ll}\text { Ari: } & \text { "If I want to show my friends and } \\
& \text { family something...I do not know, } \\
\text { all the time really." } & \\
\text { Sarine: "When I am on Instagram and } \\
\text { Snapchat. A picture is like a } \\
\text { message of words. Like an emoji } \\
\text { too." } \\
\text { Atom: "For a concept and analysis } \\
\text { diagrams. I am part of a physics } \\
\text { groups and I take pictures of } \\
\text { diagrams to talk about physics in the } \\
\text { group. It makes it easier than typing } \\
\text { it all out." } \\
\text { Tamar: "All the time. People can see what I } \\
\text { am doing or what I am talking about } \\
\text { that way." }\end{array}$ \\
\hline Videos & $\begin{array}{l}\text { "Only when I send memes to my } \\
\text { friends...they are like videos of } \\
\text { funny things. People make them and } \\
\text { post them and I share them." }\end{array}$ \\
\hline
\end{tabular}




\begin{tabular}{|l|l|}
\hline Sarine: "I don't. The only time is when I \\
post a story on Snapchat. I send \\
friends funny videos too, like \\
memes."
\end{tabular}

\subsubsection{Communication Processes}

All respondents agreed that emojis made communication easier because they themselves provide an enhanced meaning. Ari expressed: "Ya, they can make a message sound happy or angry or something and it is less words." Sarine volunteered: "Ya because they help people know what you mean. A message can sound mean but an emoji can make it sound nice. This is good for me because I am learning English and if I am talking to someone who is from Canada I am worried I might say the wrong thing." Atom asserted: "Yes they give a deeper meaning to what you're saying or they make it quick." Tamar confessed: "Yes. Always. They tell other people what you message or picture means. A picture with an emoji let's the other people know what you mean by it." The participants' responses support Lu, Xuan, et al. (2016)'s assertion that emojis are a quick way for anyone to communicate because one avoids encountering language barriers (p. 770).

\subsubsection{Emoji's Meanings}

The first emoji was unanimously understood as having a double meaning (Table 3 ). The image appears to be laughing with tears; however, it was interpreted as simply laughing or as a sarcastic remark. The respondents agree that the meaning of the emoji is dependent on the context of the message received. Three of the four participants also identified this emoji as their favourite and most used emoji. Ari and Atom reported that they did not use the second emoji. Sarine and Tamar suggested it was a sign of hesitation and anxiousness. The third emoji was also unanimously understood as having multiple meanings. Respondents associated it with situations that are humorous and flirtatious. Atom asserted that the emoji itself is a symbol for double meaning - as it is used to be coy and not directly answer or ask a question. The last emoji was unanimously understood by all the respondents to be a sign of empathy. All respondents stated they used that emoji when they are feeling sad - themselves or for someone else.

Table 3 Emoji Interpretation

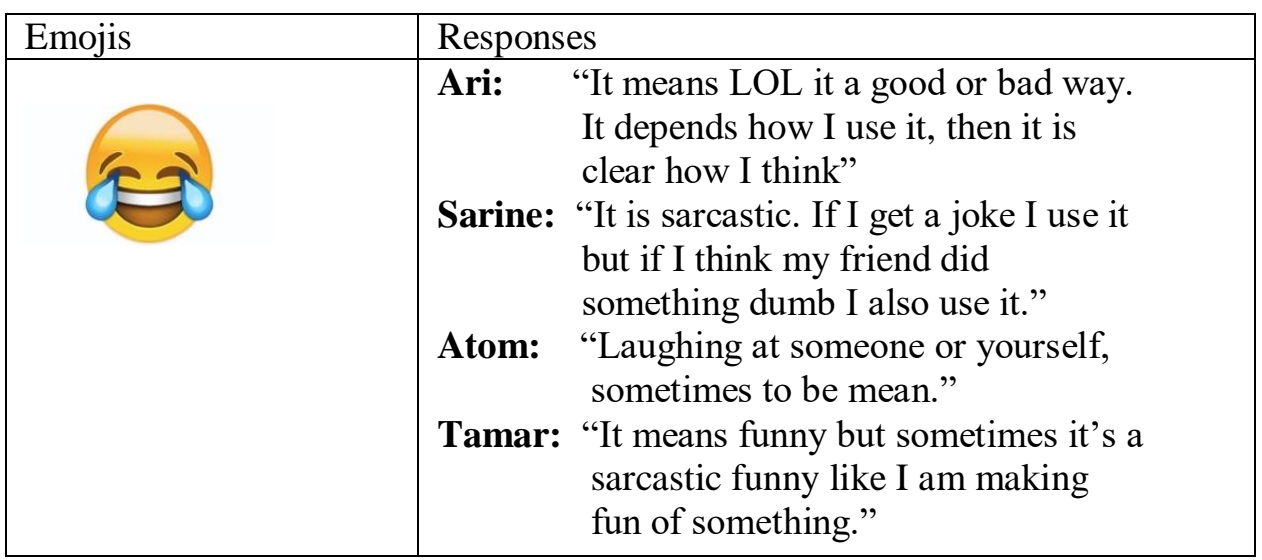




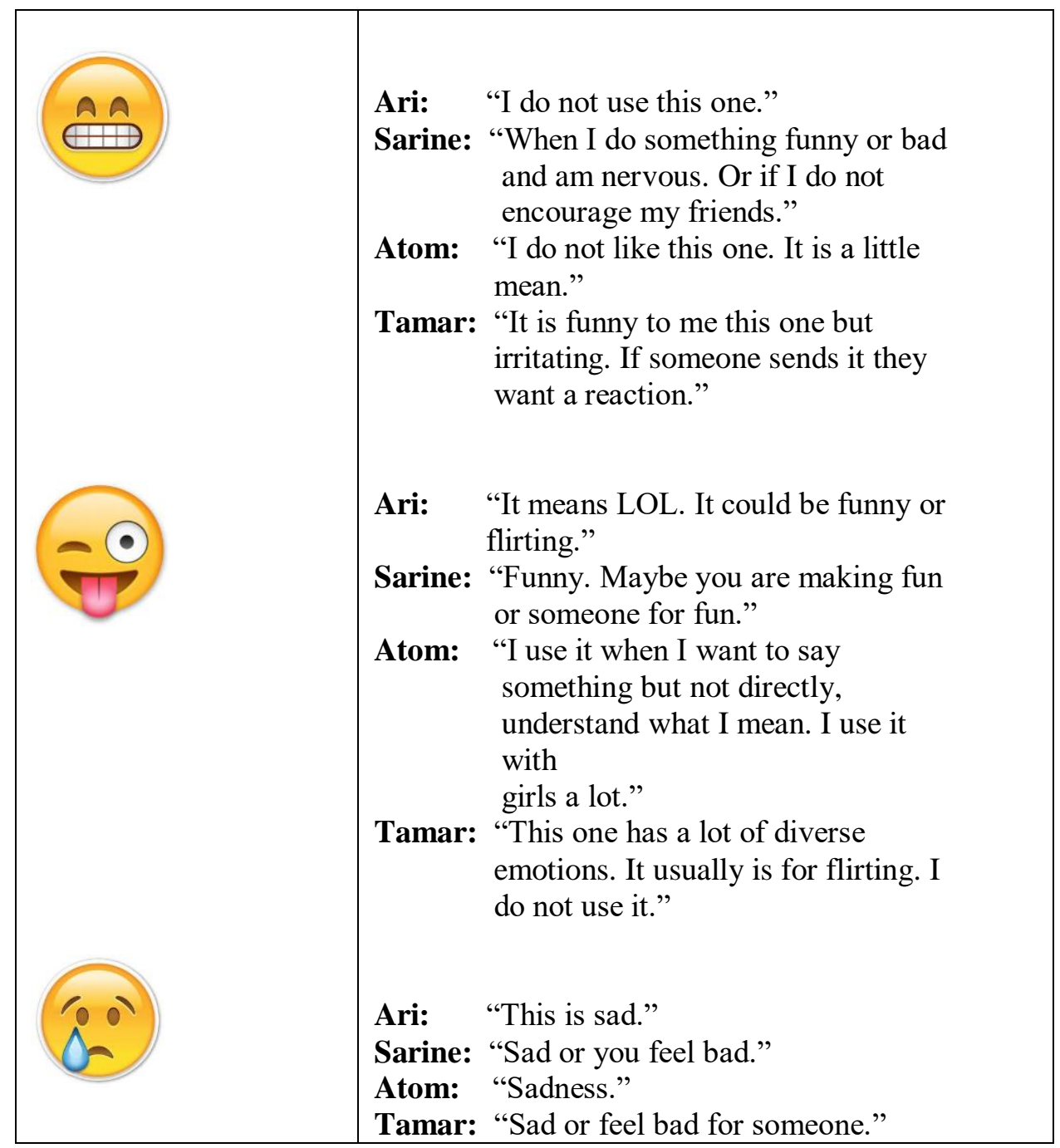

\subsection{Social Media Uses in Canada and Syria}

All four respondents indicated that the way social media were used prior to their arrival in Canada in the same manner as Canada, supporting Maitland and Xu (2015)'s findings on refugee phone usage. One question inquired about a specific Snapchat ritual referred to as streaks. Streaks are a consecutive number of snaps shared between two people over a certain number of days. A number appears beside the person's name the streaks are sent to, in order to keep track of how long the streaks are maintained. Three out of the four respondents sent streaks regularly to their friends on Snapchat. Atom divulged: "I have about 5 streaks. The longest I've ever had was 87 days. I send the routine black screen and ' $\mathrm{S}$ ' in the morning. It's fun because the numbers go up and a lot of people think it is important. It means like you are friends." All three respondents who sent streaks to friends, indicated the importance of streaks was greater in Canada in comparison to Syria.

\subsection{Most Important Parts on Social Media Platforms}

Ari expressed: "Communication I think. On social media you get to talk and read and watch videos on any subject." Sarine reported: "Education because you can learn a lot on different things from social media like news and about products. I get to learn from my family back home 
and know what is going on there." Atom revealed: "I think education, because you can read and watch in any language. Even for translation social media is good. It helps me learn English." Tamar disclosed: "The educational aspect of social media, because you learn a lot about the world and your friends." The respondents considered social media platforms as a way to engage and learn from people by interacting or through observations.

\subsection{Snapchat Observations}

I was added as a friend by all four respondents via Snapchat. All four participants use a Bitmoji. A Bitmoji is a downloadable app that allows icon users to create a cartoon-like rendering of themselves. The Bitmoji is then used as a display picture on Snapchat.

All four respondents had Snapchat stories. Each story was comprised of both videos and pictures, with different filters, stickers and emojis placed on top. The respondents' stories included images and videos from the previous day. Atom and Tamar included a location filter on their stories. All four respondents included an image of themselves in their story. None of the four included written words in their Snapchat stories.

\section{ConClusion}

Findings from this study have suggested that Armenian Syrian millennial refugees who were newly arrived to Canada were able to communicate and convey and acquire knowledge using non-text based communication. Facilitating these patterns of communication was that the culture surrounding social media and its use in Canada dictated to a great extent the way in which this information was perceived and understood. However, it remains unclear whether social media uses - for immigrant, second language learners especially - are to be regarded as a form of enrichment or a compensatory strategy. Certainly, arguments can be made for each interpretation. Is social media use beneficial or does it provide an 'out' for English language learners to give up on verbal language acquisition and settle for a restricted code, dependent on visual cues alone?

According to Doyle (1970), compensatory education attempts to "improve the educational opportunities and eliminate the differences that some students bring" (p. 39). Choice (1997) defines enrichment education as: a way to "enhance cognitive functions necessary for independent thinking and improved learning ability" (Abstract). Emojis, pictures and videos were a way to compensate for the respondents' lack of English language skills but also, arguably, enriched their repertoires and allowed them to communicate to monolingual, English language speakers. However, if this semiotic practice indeed constituted learning enrichment, is the degree of enrichment considered sufficient for the practice to continue? And how can its continued success be monitored?

Certainly, the scope of this study cannot provide sufficient evidence to support either side of the argument. This emerging area of study, coupled with "the transportation of people across national and local boundaries... [thereby creating] global economies" (Schecter \& Bayley, 2002, p. 199), invites educators and researchers to be proactive. Schecter and Bayley (2005) assert: "We see bilingualism, or multiculturalism, as part of a larger vision that regards cultural pluralism as a desirable state, one with additive potential (p. 199)." The jury is still out on the beneficial uses this new pluralistic society may make of social media and, specifically, on millennial refugees' capacity to harness these new technological devices to other literacy skills they will need in order to realize their life goals and career aspirations. 


\section{REFERENCES}

[1] Holmes, Janet and Miriam Meyerhoff. The community of practice: Theories and methodologies in language and gender research. Language in Society 28: 173-184.

[2] Lave, J., \& Wenger, E. (1998). Communities of practice. Retrieved June, 9, 2008.

[3] Wenger, E. (1998). Community. In Communities of practice: Learning, meaning, and identity (pp. 7-85). Cambridge, U.K.: Cambridge University Press.

[4] Lloyd, A., Anne Kennan, M., Thompson, K. M., \& Qayyum, A. (2013). Connecting with new information landscapes: information literacy practices of refugees. Journal of Documentation, 69(1), 121-144.

[5] Lloyd, A., Lipu, S., \& Kennan, M. A. (2010). On becoming citizens: Examining social inclusion from an information perspective. Australian Academic \& Research Libraries, 41(1), 42- 53.

[6] United, N. (1989). Convention and Protocol Relating to the Status of Refugees. Annual review of population law, 16, 175.

[7] Pottie, K., Greenaway, C., Hassan, G., Hui, C., \& Kirmayer, L. J. (2016). Caring for a newly arrived Syrian refugee family. Canadian Medical Association Journal, 188(3), 207-211.

[8] Statistics Canada. (2018, March 20). Census Profile, 2016 Census Toronto [Census metropolitan area], Ontario and Ontario [Province]. Retrieved from http://www12.statcan.gc.ca/censusrecensement $/ 2016 / \mathrm{dppd} / \mathrm{prof} /$ details/page.cfm?B1=All\&Code1 $=535 \&$ Code2 $=35 \&$ Data=Count $\&$ Geo 1=CMACA\&Geo2=PR\&Lang=E\&SearchPR=01\&SearchText=Toronto\&SearchType=Begins\&TA $\mathrm{BID}=1$

[9] Barber, S., \& Ramsay, L. (2017, May). Refugees: The New Global Issue Facing Teachers in Canada. In Global Conference on Education and Research (GLOCER 2017) (p. 347).

[10] Howe, N., \& Strauss, W. (2007). The next 20 years. Harvard business review, 85 (7-8), 41-52.

[11] Hershatter, A., \& Epstein, M. (2010). Millennials and the world of work: An organization and management perspective. Journal of Business and Psychology, 25(2), 211-223.

[12] Ivkovic, D., \& Lotherington, H. (2009). Multilingualism in cyberspace: Conceptualising the virtual linguistic landscape. International Journal of Multilingualism, 6(1), 17-36.

[13] Lu, X., Ai, W., Liu, X., Li, Q., Wang, N., Huang, G., \& Mei, Q. (2016, September). Learning from the ubiquitous language: an empirical analysis of emoji usage of smartphone users. In Proceedings of the 2016 ACM International Joint Conference on Pervasive and Ubiquitous Computing (pp. 770780). ACM.

[14] Evans, V. (2017). The Emoji Code: How Smiley Faces, Love Hearts and Thumbs Up are Changing the Way We Communicate. Michael O'Mara Books.

[15] Kennan, M. A., Lloyd, A., Qayyum, A., \& Thompson, K. (2011). Settling in: The relationship between information and social inclusion. Australian academic \& research libraries, 42(3), 191210 .

[16] Vertovec, S. (2007). Super-diversity and its implications. Ethnic and racial studies, 30(6), 10241054. 
International Journal of Education (IJE) Vol.8, No.1, March 2020

[17] Blommaert, J., \& Rampton, B. (2012). Language and Superdiversity. Diversities, 13(2), 1-36. Retrieved December 23, 2015, from http://www.mmg.mpg.de/fileadmin/user_ upload/Subsites/Diversities/Journals_2011/2011_13-02_art1.pdf.

[18] Jørgensen, J. N., Karrebæk, M. S., Madsen, L. M., \& Møller, J. S. (2011). Polylanguaging in Superdiversity. Diversities, 13(2).

[19] Blommaert, J. (2013). Citizenship, language, and superdiversity: Towards complexity. Journal of Language, Identity \& Education, 12(3), 193-196.

[20] Schecter, S. R. (2015). Language, culture and identity. In F. Sharifian (Ed.), The Routledge Handbook of Language and Culture (pp. 196-208). New York:n Routledge.

[21] Geertz, C. (1973). The interpretation of culture. New York: Basic Books.

[22] Doyle, M. (1970). WHAT IS COMPENSATORY EDUCATION?. Contemporary Education, 42(1), 39.

[23] Choice, A. G. (1998). The effect of Instrumental Enrichment on the reasoning abilities, achievement and behavior of elementary alternative education students.

[24] Schecter, S. R., \& Bayley, R. J. (2002). Language as cultural practice: Mexicanos en el norte. Routledge.

\section{Authors}

Alyssa Racco is a PhD student at York University in the Faculty of Education. Her current research interests include critical animal studies and language. 